\title{
INFORMATION SYSTEM STRATEGIC PLANNING WITH ENTERPRISE ARCHITECTURE PLANNING
}

\author{
Lola Yorita Astri ${ }^{1}$; Ford Lumban Gaol ${ }^{2}$ \\ ${ }^{1}$ Information System Department, STIKOM DB Jambi \\ Jln. Jendral Sudirman, Thehok, Jambi 36138, Indonesia, astri0206@gmail.com \\ ${ }^{2}$ Bina Nusantara University \\ Jln. K. H. Syahdan No. 9, Jakarta 11480, Indonesia, ford_lg@yahoo.com
}

\begin{abstract}
An integrated information system is needed in an enterprise to support business processes run by an enterprise. Therefore, to develop information system can use enterprise architecture approach which can define strategic planning of enterprise information system. SMP Negeri 1 Jambi can be viewed as an enterprise because there are entities that should be managed through an integrated information system. Since there has been no unification of different elements in a unity yet, enterprise architecture model using Enterprise Architecture Planning (EAP) is needed which will obtain strategic planning of enterprise information system in SMP Negeri 1 Jambi. The goal of strategic planning of information system with Enterprise Architecture Planning (EAP) is to define primary activities run by SMP Negeri 1 Jambi and support activities supporting primary activities. They can be used as a basis for making data architecture which is the entities of application architecture. At last, technology architecture is designed to describe technology needed to provide environment for data application. The plan of implementation is the activity plan made to implemented architectures by enterprise.
\end{abstract}

Keywords: Information System; Enterprise Architecture; Enterprise Architecture Planning (EAP)

\section{INTRODUCTION}

A good information system management produces easiness to access data or information in the organization. Information system is built from variety of units involved in the organization. The units involved produce different type of information from each other but still have the interconnection. [1]

Separation of information system from each unit results the lack of availability, consistency and effectiveness of information provision. Therefore, for the easiness of information accessibility, the integration of information system from variety of organization units is needed and it can produce integration of information. Integration of information system increases organization performance to speed up the whole process. [2]

The aims of information system are to provide information for each part of the organization. So that,business processes run by the organization go well and also provide solutions for problems that arise in business processes. Therefore, developing information system should be in a structured, integrated and implemented properly [3].
Enterprise is a collection of institutional tasks and support function of entities which have a common goal. In this case, enterprise consists of some divisions or units that must be managed by clear rules, and of course will need integrated information system. To develop it, enterprise can use enterprise architecture approach. [4]

Enterprise architecture is important to define enterprise strategy and also planning to be applied the information systems in the enterprise. [4]

SMP Negeri 1 Jambi is one of the formal education institutions trying to follow information technology and information system development. But in this process, this school does not follow the rules of an enterprise yet. Whereas, information system is to fulfill the needs of few units that is not integrated each other, for example: in computer lab, for payroll, attendance recap and grade recap.

Enterprise architecture model is required to combine different elements in one that will develop and manage enterprise architecture in a better direction [5]. One of the methodologies for it is Enterprise Architecture Planning (EAP). The results of this method are data, application and technology architecture's blue print. 


\section{METHOD}

\section{Planning Initiation}

Planning initiation means defining track for enterprise architecture planning, including which methodology to use, who should be involved, and what toolset to use. This leads to producing a workplan for EAP and securing the management commitment to go through the next phases. [6]

Input: core business of organization is academic process, from admission of new students until graduation ceremonial. Process: defining the scope of the organization as an enterprise and determine the purpose of Enterprise Architecture Planning (EAP). Output: (a) The tangible deliverable is the EAP project workplan that specifies the phases and steps necessary to accomplish the goals of EAP, namely, to develop the architectures and implementation plans. (b) The intangible deliverable from this phase is the support and commitment of management throughout the enterprise for successfully completing EAP.

\section{Business Modeling}

The purpose of the business model is to provide a complete, comprehensive, consistent knowledge base that can be used to define the architectures and implementation plans.

Input: organizational structure consists of school principal, vice principal, teachers, students, administrations and stakeholder which are related with this organization. Process: defining functionality of whole organization units which consists of main units and support units, and categorizing function of organization units based on organization structure, for example: main function related with vice principle, academic unit, administration unit, and support unit related with librarian, laboratories and administrations unit. Output: identifying functions each organization units because defining the business is essential before defining architectures; and the quality of the architectures is derived from the quality of the business model.

\section{Current Systems and Technology Architecture}

The purpose of this phase of EAP is to document and define all of the systems and technology platforms in use within the enterprise. The major deliverable of this phase is called information Resource Catalog (IRC). The IRC is at a high summary level and does not go into exhaustive detail for every system. It is not a data dictionary that documents files, data elements, and records, and it is not an equipment inventory of all items used for computing.

Input: determining the scope, objectives, and IRC workplan, data collection, collect the IRC data, enter data, validate and review the draft of the IRC and draw schematics. Process: determining of main function such as academic system information and support function such as: inventory information system; defining system in each main function and support function; determining of main activities and support activities; analyzing of business process from each main and support function; analyzing current system. Output: information Resource Catalog (IRC).

\section{Data Architecture}

The Data architecture identifies and defines the major kinds of data that support the business functions defined in the business model. The data architecture consists of data entities, each of which has attributes and relationship with other data entities.

Input: function definitions, information source forms, samples of information sources, interview notes, existing systems and file descriptions, other data architectures or database designs. Process: determining data entity each main and support functions, creating Entity Relationship Diagram for each function, mapping data entities to business function, defining of information architecture. Output: Entities list according to business function and ERD each function.

\section{Applications Architecture}

The purpose of the applications architecture is to define the major kinds of applications needed to manage the data and support the business functions of the enterprise. The applications architecture is not a design for systems, nor is it a detailed requirements analysis. It is a definition of what applications will do to manage data and provide information to people performing business functions. Input: lists candidate applications, define the applications and relate applications to functions. Process: defining list candidate applications, description of application, analyzing impact to current applications. Output: list of new applications.

\section{Technology Architecture}

The purpose of the technology architecture is to define the major kinds of technologies needed to provide an environment for the applications that are managing data. It is definitions of the kinds of technologies - referred to as platforms - that will support the business with a shared data platform provide the means for collecting data from any unit business. Input: list of application candidate, technology platform. Process: identifying technology principles and platforms, defining the platforms and distribution, relating the technology 
platform to applications and business function, distributing the technology architecture. Output: technology architecture.

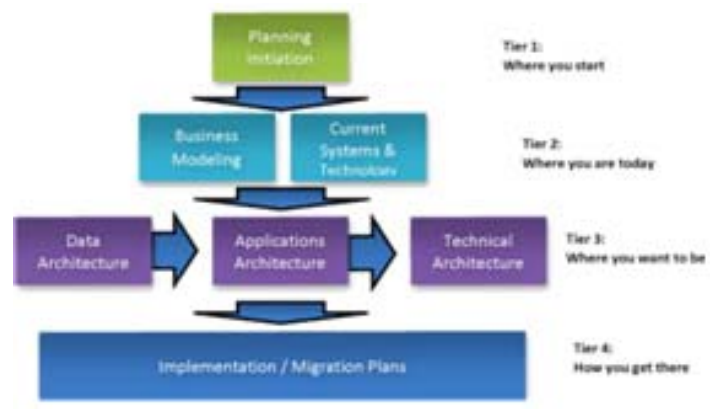

Fig. 1: Components of Enterprise Architecture Planning

\section{RESULTS AND DISCUSSION}

\section{Porter's Value Chain Model Analysis}

Functional business model which is run by SMP Negeri 1 Jambi can be described with Porter's value chain model. This model describes interconnection between primary function and support function that are run by the organization to reach the goal that has been set [7]. See Figure 2.

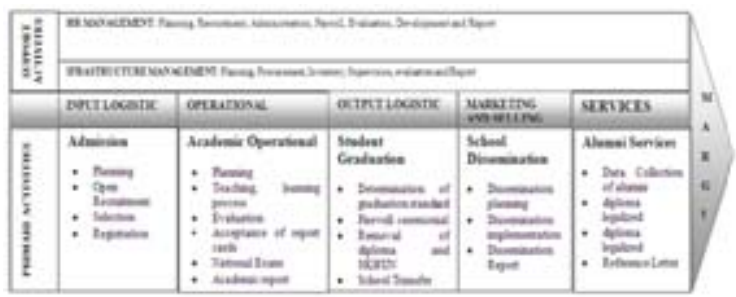

Fig. 2: Porter’s Value Chain Model Analysis

\section{Data Architecture}

The next step is building data architecture to define and identify the data that are used by enterprise to support business function. It is also the first step of information system architecture design because the quality of the data is the basic product of information system function. Data architecture describes all of data entities to be generated, managed and used by all functions or business processes.

\section{List Entities}

In this step, list entities is made based on primary business function and support business function which are already define. This identification also depends on information resource catalog.

The data entities have relationship with other data entities, because of its interdependence.
To illustrate the relationship between the data entities will be constructed using conceptual data model diagram ERD. ERD is a diagram that illustrates the relationship between data entities logically. A data entity may engage in more than one area of function, therefore some ERD can use the same data entity. See Figure 3.

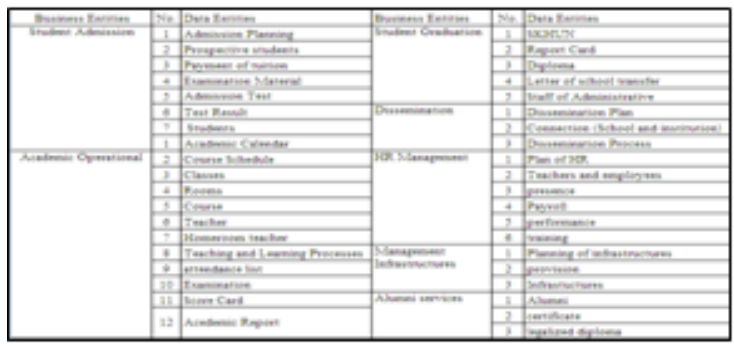

Fig. 3: Entities of each Business

\section{Information Architecture}

Identification of information system and its subsystem that will be developed is to define information architecture. The identification may use a diagram that shows the relationship between data entities and system processes. It also makes organization able to understand data requirements of subsystem during the development of subsystems to maximize data sharing.

The first step of information system determination is to identify main system based on entities data relationship matrix and function or business process that has been made. Then, the data entities are labeled with 'C' or 'CUR' and grouped based on business function that creates it so that groups of data needed in every area of business functions are formed. See Figure 4.

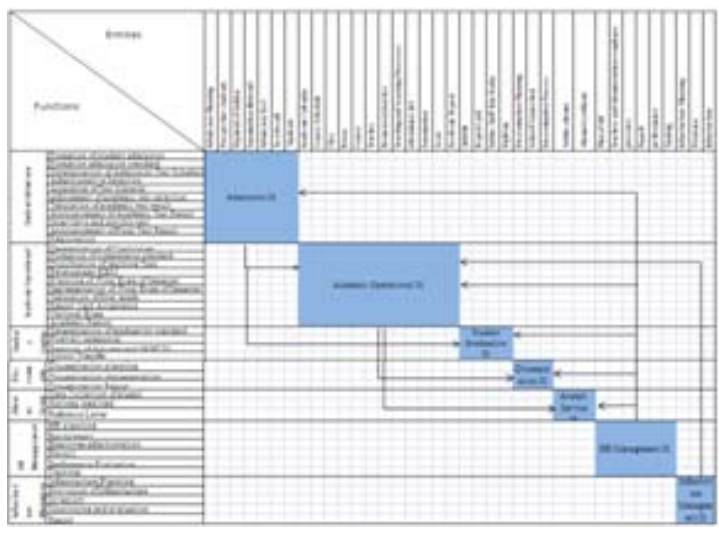

Fig. 4: Information Technology

Systems will link each other because data in one system will be required by another system. For example, student data entities are required by academic operational system and student graduation system. The requirement of data entities 
in each system is labeled as ' $U$ ' or ' $R$ '. Based on the data requirements in each system, the flow of data is determined [4].

\section{Application Architecture}

The purpose of the application architecture is to define the major kinds of application needed to manage the data and support the business functions of the enterprise. The application architecture corresponds to the Zachman Framework for information system. It is the second stage of the three stages architectures for EAP [6].

\section{List of candidate application}

Developing application architecture started with candidate's application identification that is needed to manage data and support the business. It is automation and supported by information technology. Identification of candidate applications made by considering the data entities, business processes and information resources catalog predetermined. Applications required to support each business function can be grouped into a functional information system and are named according to the functions they support such academic information systems, human resource information systems and so on. This is also conducted by considering the information architecture that has been built previously [8].

The main business function is managed using academic information system in conducting academic operational. Some of the applications are maintained catalog information resources; they are admission test result management application, curriculum application, schedule application, grade management application, student administration application and academic report application. While the application should be developed are addition application, PBM administration application, transfers school application, SKHUN application and diploma application

\section{Configuration Platform Technology}

Technology platform configurations are closely related to the strategy of distributing applications and data as well as defining technology platform that will be placed on the business location of organizational units which will make sharing data.

Business location is the location where each unit of the organization conducts its business activities and also the place where the necessary data and specific applications [9].

Development of technology architecture is based on a matrix of business processes with data entities and applications needed to manage the data and support the business functions that have been defined previously and then connected with a business location in needed. See figure 5.

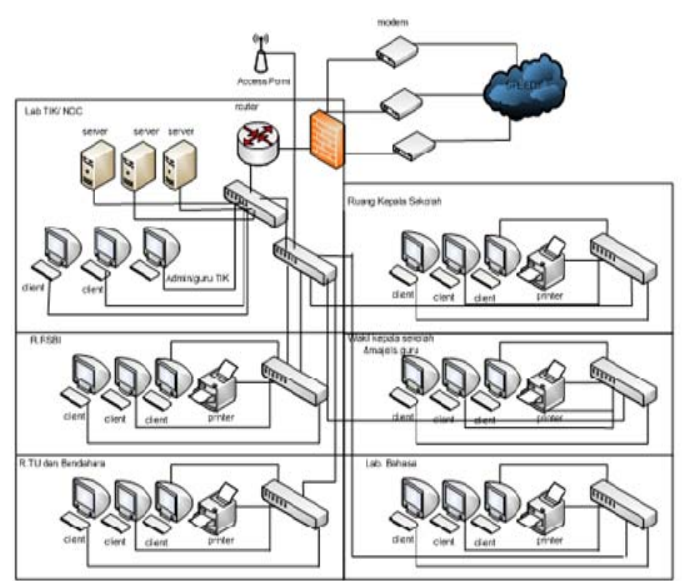

Fig. 5: Conceptual Network of Enterprise

\section{CONCLUSION}

Based on the analysis and development of enterprise architecture, it can be concluded as follows. (1) Business activity in SMP N 1 Jambi is divided into two main activities and support activities. The main activity consists of new admissions process, academic operations, student graduation, dissemination SMP N 1 Jambi and services comprising of alumni while supporting human resource management and management of facilities or infrastructure. (2) Many activities that are non-value-added processes exist in academic administration based on the analysis conducted. (3) Efficiency and effectiveness of time can be done by utilizing the support of IS/IT. (4) Having analyze the current state of the business process, it can be seen that the use of IS/IT in supporting functions/business processes have not been efficient. (5) Data architecture development entities generate 39 data required by the business which can be created, updated and used by business processes. (6) Development of new applications needs to be integrated with legacy applications are retained to form the integrated enterprise in supporting of business and providing data or information that is needed by all business units. (7) The development of technology architecture generating a conceptual enterprise network that enables data sharing and collaboration among business units.

\section{REFERENCES}

[1] K. C. Laudon, \& J. P. Laudon, Management Information Systems: Managing the Digital Firm, 11th Ed., New Jersey: Pearson Prentice Hall, 2010.

[2] L. Jessup, \& J. Valacich, Information Systems Today: Managing in the Digital World, 3rd Ed., Upper Saddle River, New Jersey: Pearson Prentice Hall, 2008. 
[3] J. Jeston, \& J. Nelis, Business Process Management: Practical Guidelines to Successful Implementation, Oxford, United Kingdom: Elsevier, Ltd, 2006.

[4] W. A. Ruh, dkk, Enterprise Application Integration, New York: John Wiley \& Sons, 2001.

[5] H, Kerzer, Strategic Planning for Project Management using a Project Management Maturity Model, New Jersey: John Wiley \& Sons, 2001.

[6] S. H. Spewak, \& S. C. Hill, Enterprise Architecture Planning: Developing a Blueprint for Data, Application and Technology, Princeton: John Wiley \& Sons, 1992.

[7] J. Ward, \& J. Peppard, Strategic Planning for Information Systems, 3rd Ed., West Sussex, England: John Wiley \& Sons, 2002.

[8] D. Minoli, Enterprise Architecture A to Z: Frameworks, Business Process Modeling, SOA, and Infrastructure Technology. United States of America: CRC Press Taylor \& Francis Group, 2008.

[9] J. Schekkerman, How to Survive in The Jungle of Enterprise Architecture Framwork, 2nd Ed., Trafford, 2004. 